\title{
Rocuronium-sugammadex, an alternative to succinylcholine, as a muscle relaxant during electroconvulsive therapy
}

\author{
Yuji Kadoi
}

Received: 19 April 2011/ Accepted: 25 April 2011/Published online: 18 May 2011

(C) Japanese Society of Anesthesiologists 2011

In reply:

I thank Dr. Yalcin et al. for their interest in our case report. As they point out, our case report has several limitation, which we would like to clarify. First, our article is a case report and, as such, the number of patients is very small. It needs to be noted that sugammadex has only recently become available in Japan and that the purpose of our study was to examine the potential efficacy of rocuronium-sugammadex as an alternative to succinylcholine for achieving muscle relaxation during electroconvulsive therapy (ECT). We recognize that large-scale prospective studies are needed to confirm the use of rocuronium-sugammadex as an alternative agent to succinylcholine. Secondly, the small sample size $(n=5)$ prevented the identification of a statistically significant difference in this study. In addition, the age of the subjects (relatively elderly, $62.8 \pm 5.9$ years) [1] and sugammadex dose $(16 \mathrm{mg} / \mathrm{kg})$ [2] used in this study may have had some effects on our results. Consequently, further study is needed to identify the optimal dose of sugammadex required for the reversal of rocuronium-induced muscle relaxation during ECT.

Conflict of interest The authors have no conflicts of interest in association with this article.

\section{References}

1. McDonagh DL, Benedict PE, Kovac AL, Drover DR, Brister NW, Morte JB, Monk TG. Efficacy, safety, and pharmacokinetics of sugammadex for the reversal of rocuronium-induced neuromuscular blockade in elderly patients. Anesthesiology. 2011;114: 318-29.

2. Pühringer FK, Rex C, Sielenkämper AW, Claudius C, Larsen PB, Prins ME, Eikermann M, Khuenl-Brady KS. Reversal of profound, high-dose rocuronium-induced neuromuscular blockade by sugammadex at two different time points: an international, multicenter, randomized, dose-finding, safety assessor-blinded, phase II trial. Anesthesiology. 2008;109:188-97.

This author's reply refers to the letter to the editor at doi:10.1007/s00540-011-1164-x.

\section{Y. Kadoi $(\bowtie)$}

Department of Anesthesiology, Gunma University

Graduate School of Medicine, 3-39-22 Showa-Machi,

Maebashi, Gunma 371-8511, Japan

e-mail: kadoi@med.gunma-u.ac.jp 